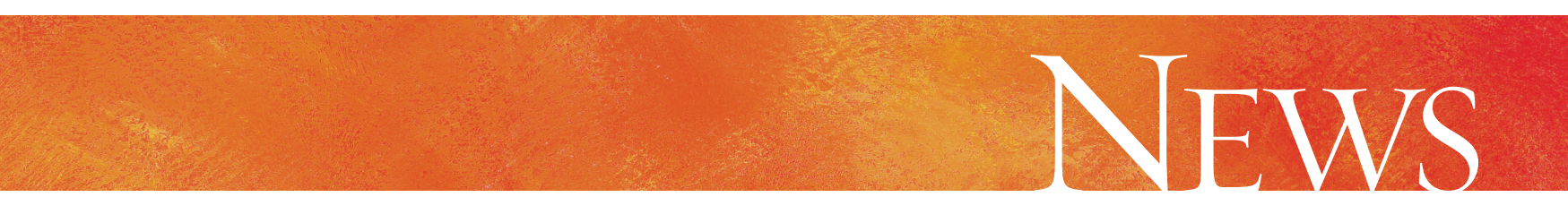

\section{Sir Frederick Banting home-}

\section{stead sold to developer,}

\section{family outraged}

$\mathrm{T}$ he incongruities seem startling, primarily because it's a tale involving the honour and memory of Canadian icon Sir Frederick Banting, who unselfishly gave diabetes sufferers the gift of insulin for the princely sum of $\$ \mathrm{I}$.

In fact, the altruism and generosity of spirit that lay behind the Nobel laureate's decision to sell the rights to his discovery to the University of Toronto for a song seem entirely absent in an embittered and complex imbroglio that has erupted over his birthplace and left his descendants levelling accusations of greed and betrayal of trust.

At issue is the fate of the family homestead in New Tecumseth, Ont., roughly $35 \mathrm{~km}$ southwest of Barrie, which was bequeathed to the Ontario Heritage Society (OHS) for \$I in I999 by descendant Edward Banting in the belief that it was the best way to ultimately protect the Ioo-acre farm as a cultural heritage site.

What has ensued is a mind-boggling brouhaha in which the OHS is essentially opposing heritage designation for the birthplace of one of Canada's most illustrious sons and has sold off the land to a housing developer for the much more princely sum of about $\$ 2.2$ million.

While doing so, the society spurned a purchase offer from the town of New Tecumseth and the Sir Frederick Banting Legacy Foundation that would have seen a sizable portion of the homestead set aside to create a camp for youth with diabetes, an interpretive centre and a museum, but would only have netted the OHS \$I million. The offer, which was being negotiated with the assistance of provincially appointed facilitator Alan Wells, would have seen 30 acres of the homestead sold to developer Mattamy Homes for \$I million. Those monies would have flowed through to the OHS.

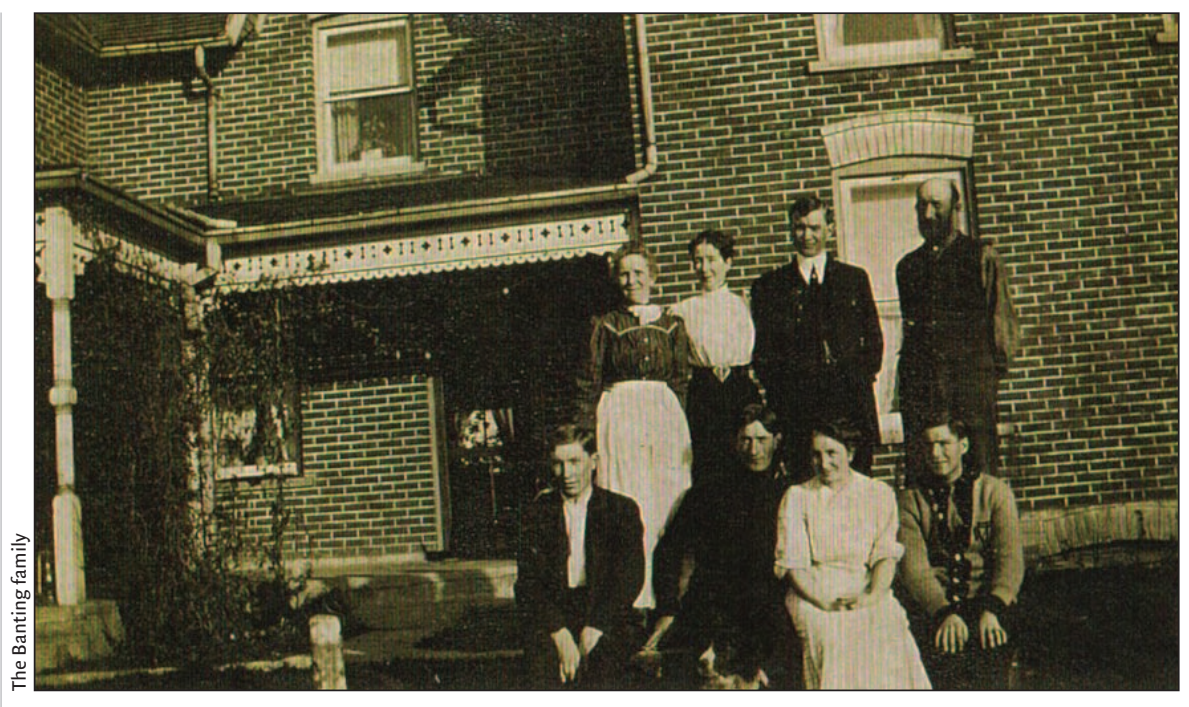

Members of the Banting family and friends being photographed in front of the south side of the family home in 1910. Pictured are, back, left to right: Banting's mother (Margaret), family friends Ella Knight and Sam Graham, Banting's father (William); and front, left to right: Banting, brother Fred, sister Essie and brother Ken. Banting was born in the room directly behind his father.

The remaining 70 acres would have been designated as heritage property and turned over, along with a \$200 o00 donation from Mattamy Homes, to the foundation for the camp and historical/ tourism initiatives.

Instead, the OHS accepted an offer from developer Benny Marotta, owner of Solmar Development Corporation, under which 96 acres will be used for new subdivisions and a scant 4 acres preserved. Marotta, who declined to be interviewed, also committed to a $\$ 100,000$ donation to help restore deteriorating buildings on the homestead.

The New Tecumseth council countered by voting to assign heritage designation to the northerly 70 acres of the homestead. Rather than support the designation, the OHS has appealed it to the Ontario Conservation Review Board.

The ruling, expected to be released this spring, is not inconsequential in that it may preclude the building of new houses on much of the property and, theoretically, may scuttle the sale. The land is currently zoned as agricultural, so if Marotta wants to build homes, he'll need zoning amendments and approval for severance from the council, which wouldn't be possible if the Ontario Conservation Review Board sides with the town of New Tecumseth.

As far as Mayor Mike MacEachern is concerned, the matter is entirely unresolved. "To my knowledge, the sale has not been completed."

OHS president Chris Oslund declined to be interviewed about the society's rationale for the sale or for opposing heritage designation. But last December, he penned a letter stating that "the New Tecumseth offer was less remunerative than another offer received by the OHS Foundation and also entailed a three-year deferred payment.... While the municipality has now initiated a heritage designation of some 70 acres of the property, the original offer was silent on the matter of conservation and protection of the homestead and its buildings, and meeting the costs involved. Indeed, this still remains an unanswered issue of some concern to the OHS and it would be most willing to discuss a heritage designation regarding the building precinct." 
That being, of course, the 4 acres, which the Banting legacy foundation says is completely inadequate for a camp for youth with diabetes.

Ontario Premier Dalton McGuinty, who appointed Wells to facilitate the New Tecumseth offer, and Minister of Culture Caroline Di Cocco declined comment. But Simcoe-Grey MPP Jim Wilson, whose private member's bill, the Frederick Banting Homestead Preservation Act, appears stalled in the Ontario legislature, and Simcoe-Grey MP Helene Guergis have accused the OHS of outright betrayal and vowed to use every weapon in their arsenals to stall the sale. "A man's legacy is being completely disregarded," said Guergis in a press release. "He changed millions of people's lives around the globe. I am deeply saddened and quite frankly appalled at the actions of the OHS."

The entire affair has outraged Bob Banting, family representative and great-nephew of Sir Frederick. "The OHS and the Town of New Tecumseth - and our family - had been bargaining in good faith for months. The OHS sold our Canadian heritage to the highest bidder: sheer greed prompted this. My uncle, Edward Banting, bequeathed the property to the OHS because he wanted it protected. After he died in 1999, they got the land free and clear."

"The OHS knew the family have always had heritage preservation in mind," adds Banting, who has accused the OHS of being grossly negligent in their maintenance of buildings on the property, even while earning rental income from the farm land. "We estab-

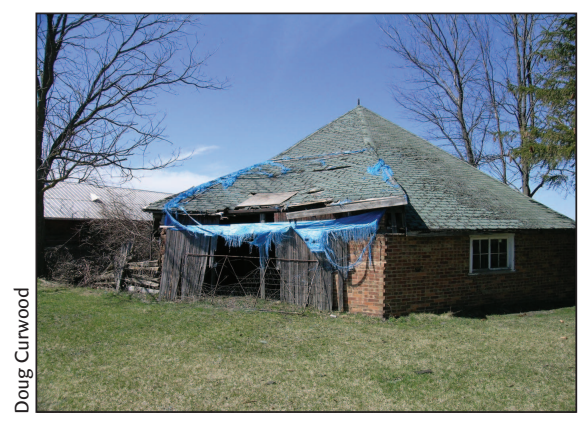

The Banting family charges that the Ontario Heritage Society reneged on a commitment to maintain homestead buildings in good condition.

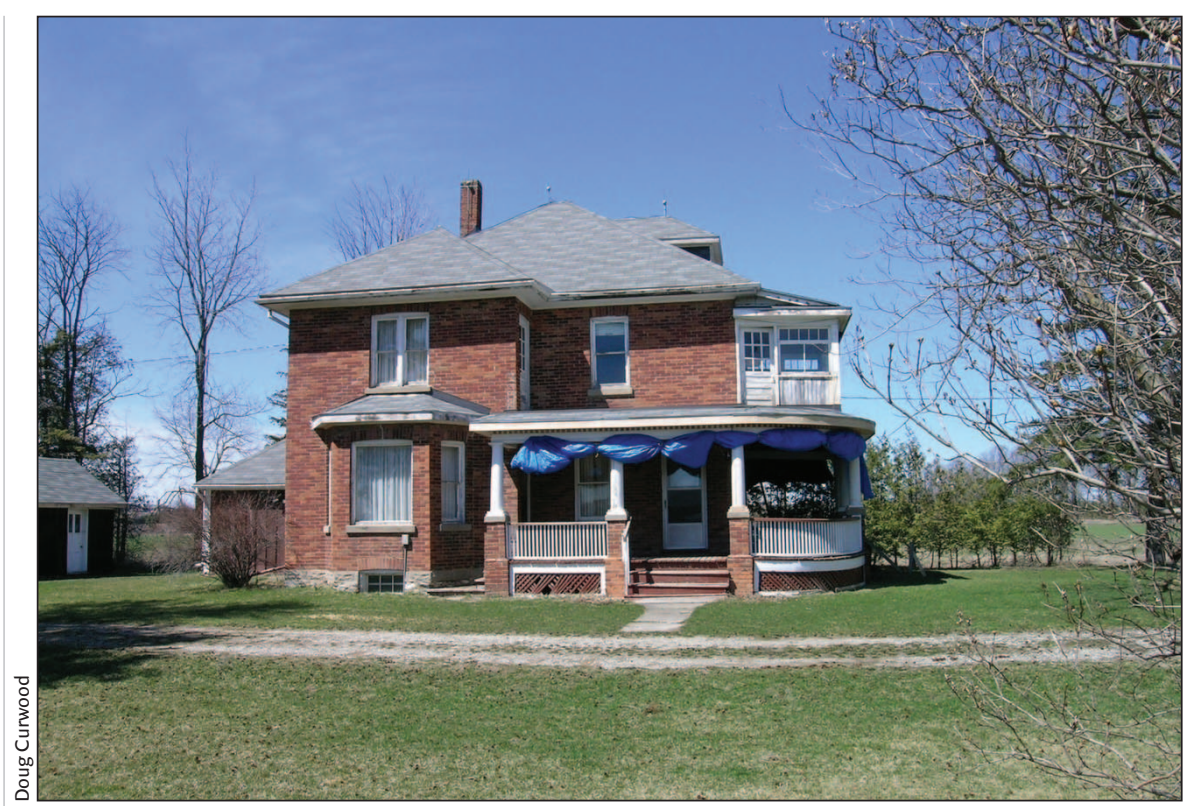

The Sir Frederick Banting Legacy Foundation and town of New Tecumseth had proposed using the family home as the base for a camp for youth with diabetes, an interpretive centre and a museum honouring the discoverer of insulin. lished the Sir Frederick Banting Legacy Foundation at their request. We've received donations from doctors and people all over Canada and the world. Our goal has always been to create a camp for diabetic children."

"If this sale goes through, a lawsuit is inevitable," Banting adds. "And the family will return all donations to the Foundation to the donors."

Further compounding the issue is a debate over the historical significance of the property. While Banting was born there Nov. I4, I89I, and his family insists his heart always lay with the homestead, some historians argue that the London, Ont., home, where he lived between 1920 and I92I and where he made his discovery, is the more significant site.

That home was designated the Banting House National Historic Site of Canada in 1997. His bedroom is carefully preserved in recognition of his medical eureka moment: before dawn on Oct. 3I, I920, Banting leapt from the humble bed to scribble notes for what would become the logic pointing to the discovery of insulin.

Site curator Grant Maltman explained, "This room is a shrine. I find people weeping in this room, who write notes of thanks to Dr. Banting, which we keep a record of, right here."

With a nod to OHS having a dilemna over what constitutes heritage, Maltman says Edward Banting's I988 unpublished history, The Grant Family History, states that "in I925, the large old house was torn down to the ground and a smaller 8 room house was built."

Bob Banting dismisses that as an OHS fiction aimed at devaluing the significance of the property. The I925 changes saw an addition built onto the house, while renovations were made to its original core, he says. But the foundation, floors and the room in which Frederic was born remain intact. Katharine Fletcher, Quyon, Que.

DOI:I0.I503/cmaj.0706r3
To follow the ongoing saga, visit the Banting House National Historic Site: www.diabetes.ca/Section_About/BantingIndex.asp Similarly, to review letters of support, published articles and more images of the homestead, check the Save Frederick Banting's Birthplace Web site at www.discoveryofinsulin.com/feedback.htm 